\title{
Cows' milk induced intestinal bleeding in infancy
}

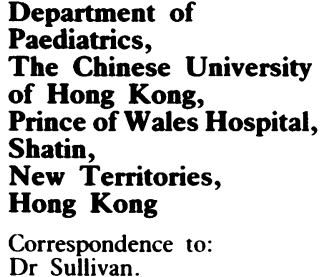

Peter B Sullivan

Current United Kingdom Department of Health recommendations on infant feeding state that 'milks considered suitable for inclusion in the diet of infants from the sixth month are human milk, infant formulas, follow-up milks and whole pasteurised cow milk'. ' Recently, however, controversy has arisen as it has been suggested that ordinary cows' milk should not be given before 1 year of age because of its relatively low iron and vitamin content, ${ }^{2}$ and because it is said to be associated with subclinical but appreciable gastrointestinal bleeding in infancy. ${ }^{3}$

This review aims to examine published work relating to the association between feeding cows' milk to infants and small children and the subsequent development in them of blood loss from the gastrointestinal tract.

It has been established that normal infants lose small amounts of blood in their stools; it has been estimated that the average 'physiological' loss of blood is $0.64 \mathrm{ml} /$ day (range $0 \cdot 17-2.5 \mathrm{ml} /$ day) ${ }^{4}$ Although the presence of gross blood in the stool (haematochezia) is obvious, detection of occult gastrointestinal blood loss is more difficult. Interpretation of the available published reports is complicated by the application of tests of differing sensitivity and specificity. One of the most sensitive methods for the identification of occult enteric blood loss detects chromium-51 $\left({ }^{51} \mathrm{Cr}\right.$ ) labelled erythrocytes in incinerated faeces. ${ }^{4-7}$ Other workers have used the orthotolidine reaction to detect faecal occult blood. ${ }^{8}{ }^{9}$ Most workers, however, have used the guaiac test; orthotolidine gives a positive result with blood in a 1:20 000 dilution with saline, whereas guaiac gives a positive result in a 1:100 to 1:5000 dilution. Guaiac is a colourless leucodye that becomes coloured in the presence of hydrogen peroxide and haemoglobin. Unfortunately, this test reacts with many non-haemoglobin substances and poor sensitivity and specificity may confound interpretation; the commerical guaiac Hemoccult test ${ }^{310}$ is known to underestimate blood loss in stools. ${ }^{11}$ On the other hand, the highly sensitive tests may not be specific and carry a high false positive rate.

Specific and quantitative tests for the determination of faecal haemoglobin (for example, the HemoQuant test) have been developed $^{12}$ and used to measure blood loss from the gastrointestinal tract of infants. ${ }^{3}$ HemoQuant is a quantitative, exquisitely sensitive test specific for faecal haem which utilises purification methods that remove non-haemoglobin porphyrin derivatives (for example, chlorophyll). The assay is based on the chemical conversion of non-fluorescing haem to intensely fluorescent porphyrins. Proof that a positive result represents haem derived porphyrin is based on its solubility, characteristic spectral and chromatographic properties, and on the finding that it increases proportionately with ingested blood. ${ }^{12}$ Alquist $e t a l$, in a comparative study, found the HemoQuant test to be considerably more sensitive and specific in the detection of faecal occult blood than the Hemoccult test. ${ }^{13}$ HemeSelect (SmithKline Diagnostics), the latest addition to the European market, is a sensitive and specific immunological test for faecal occult blood based on reverse passive haemagglutination which has yet to be applied to the study of occult blood loss in children.

\section{Iron deficiency anaemia and gastrointestinal} blood loss

The fact that some infants with iron deficiency anaemia have an increased gastrointestinal blood loss has been recognised for many years. Rasch et al using chromium-51 labelled erythrocytes, showed that anaemic infants (aged 8-23 months) had a greater gastrointestinal blood loss than non-anaemic infants. ${ }^{5}$ In subsequent early studies approximately half the number of cases of infants with iron deficiency anaemia were found to have occult blood in their faeces: Wilson et al, revised their initial figure of $40 \%{ }^{14}$ based on the guaiac test to $50 \%$ in an extended study in which they used the ${ }^{51} \mathrm{Cr}$ erythrocyte labelling technique. ${ }^{7}$ Hoag et al, reported that $37 / 64(58 \%)$ of iron deficient patients (aged 7-17 months) had positive guaiac tests compared with only $5 / 65(8 \%)$ of normal subjects; furthermore, using faecal recovery of intravenously administered radioactive iron $\left({ }^{59} \mathrm{Fe}\right)$, these workers calculated that over the three to four week period of observation anaemic infants were losing a mean of $41 \mathrm{ml}$ of blood in their stools and they concluded that occult blood loss appeared to be a significant factor in the development of iron deficiency in early childhood. ${ }^{15}$

\section{Iron deficiency anaemia, gastrointestinal} blood loss, and cows' milk

The association between gastrointestinal blood loss, iron deficiency anaemia, and ingestion of whole cows' milk was suggested by several early studies. ${ }^{691617}$ Gryboski, in a seminal study, ${ }^{16}$ examined 21 children (age range 2 days to 30 months) with chronic diarrhoea whose diagnosis of gastrointestinal milk allergy fulfilled the 
criteria of Goldman et al, which require that the symptoms must subside after the elimination of milk from the diet; they must recur within 48 hours after a trial of feeding milk; three challenges must be positive and similar; and the symptoms must subside again after each challenge reaction. ${ }^{18}$ All the children in this study had either occult (method not stated) or gross blood in their stools as well as evidence of a microcytic, hypochromic anaemia. Rectal biopsy in eight infants showed a proctitis which reverted to normal after milk elimination. Morton et al found that the introduction of whole cows' milk before the age of 6 months was associated with iron deficiency at this age and at 1 year, though they were unable to show a correlation between occult blood loss in the stool and iron status in infants of 1 year of age. ${ }^{19}$

These studies, though suggesting that whole cows' milk can induce faecal blood loss of sufficient magnitude to contribute to iron deficiency in anaemic infants, do not address the question of whether substantial blood loss can be caused by feeding whole cows' milk to normal infants. The answer to this was sought by Ziegler et al, who undertook a prospective study of normal infants to quantify intestinal blood loss and iron nutritional status. ${ }^{3}$ Fifty two infants entered the trial at 168 days of age and were assigned at random to receive either pasteurised cows' milk or a milk based formula. Initially, 31 infants had been breast fed and 21 had been formula fed. With the feeding of whole cows' milk, the proportion of guaiac positive stools increased from $3 \%$ at baseline to $30 \%$ during the first 28 days of the trial $(p<0.01)$, whereas the proportion of guaiac positive stools remained low $(5 \%)$ with the feeding of formula milk. Although the proportion of guaiac positive stools among whole cows' milk fed infants decreased later, it remained significantly greater for the entire trial $(p<0.01)$. Stool haemoglobin concentration increased markedly with the introduction of whole cows' milk, increasing from a mean (SD) of 622 (527) $\mu \mathrm{g} / \mathrm{g}$ dry stool at baseline to 3598 (10 479) $\mu \mathrm{g} / \mathrm{g}$ dry stool $(p<0.01)$ during the first 28 days of ingestion of whole cows' milk. Among infants fed formula milk, stool haemoglobin did not increase and was significantly less than in the group fed with whole cows' milk $(\mathrm{p}<0.01)$. In infants fed whole cows' milk, the increase in haemoglobin concentration tended to be greater for those who had initially been fed human milk than for those who had initially been fed formula milk. Notably, iron nutritional status was not significantly different between the two feeding groups, although one infant became iron deficient after four weeks of ingesting whole cows' milk. Ziegler et al concluded that normal infants lose measurable amounts of blood in their faeces at all times and that feeding with pasteurised cows' milk leads to increased intestinal tract blood loss in a large proportion of normal infants. ${ }^{3}$ Moreover, some infants appear to be sensitive to pasteurised cows' milk and may lose large amounts of blood such that the amount of iron lost is nutritionally important. In the absence of gastrointestinal blood loss, the estimated requirement for absorbed iron is about $0.6 \mathrm{mg} /$ day during the first year of life and Fomon et al calculated that enteric blood loss of $3 \mathrm{ml} /$ day in anaemic subjects represented a loss of iron of $0.9 \mathrm{mg} / \mathrm{day} .^{20}$

The findings of Ziegler $e t a l^{3}$ contrast with those of a much larger study by Thomas et al. ${ }^{21}$ These workers, who also used faecal haemoglobin concentration in an assay which could detect as little as $1 \mathrm{mg}$ of haemoglobin per gram of stool, found similar levels of enteric blood loss in infants receiving whole cows' milk (4/140 (3\%)), human milk (7/338 (2\%)), and formula milk (6/314 (2\%)). Thomas et al thus concluded that the prevalence of intestinal bleeding in healthy 6-12 month old infants receiving fresh whole cows' milk and other supplementary foods is low.

Whole cows' milk and heat treated cows' milk In many of the early studies referred to, young infants were fed homogenised, pasteurised whole cows' milk. Wilson et al, using the ${ }^{51} \mathrm{Cr}$ labelled red blood cell technique, showed abnormal gastrointestinal bleeding in 17/34 anaemic children (aged 6-25 months) fed with whole cows' milk. ${ }^{7}$ There was, unfortunately, no search for the site of bleeding or rectal histology performed in this otherwise well conducted study. In eight of their infants the whole cows' milk induced bleeding did not decrease despite iron treatment as long as whole cows' milk was ingested.

Wilson et al also observed a dose dependent effect wherein the amount of whole cows' milk ingested was proportional to the amount of faecal occult blood loss; in one patient faecal blood loss of $9.3 \mathrm{ml} /$ day was observed when the subject was consuming $2230 \mathrm{ml} /$ day of milk and this decreased to a loss of $1.2 \mathrm{ml} /$ day when consumption was reduced to $300 \mathrm{ml} /$ day. This dose dependent effect might imply that the mechanism of damage could be via some direct 'toxic' effect of whole cows' milk on the gut ${ }^{22}$ especially as, at this stage, no classical immunological mechanism had been shown to account for the phenomenon. The likelihood of an antigenic effect of whole cows' milk was indicated by Wilson $e t$ al, who also noted that feeding a heat processed cows' milk proprietary formula stopped abnormal enteric bleeding, leading them to speculate that heat labile proteins such as bovine serum albumin in whole cows' milk may be the aetiological factor responsible for the bleeding. ${ }^{7}$ Kilshaw et al showed that animals fed heat treated milk $\left(121^{\circ} \mathrm{C}\right.$ for 20 minutes) produced circulating antibodies to $\beta$ lactoglobulin and casein, although titres were lower than for unheated milk. ${ }^{23}$ In this study $x$ casein was unaffected by heat treatment whereas $\beta$ lactoglobulin and $\alpha$ lactalbumin were denatured. May et al, also found that heat treatment significantly decreased the serum antibody response to ingested whole cows' milk; however no clinical nor immunological disorders were noted by these workers in infants with antibody responses to whole cows' milk. ${ }^{24}$ It is probable that methods of preparation and manufacture of milk formulas alter their antigenicity; SMA liquid, which is sterilised, is less sensitising than SMA powder, which is spray dried. ${ }^{25}$ 
Other reports have underlined the difference between whole cows' milk and heat treated formula. Using albumin turnover following the intravenous injection of $4.44 \mathrm{kBq}$ of $\left[{ }^{131} \mathrm{I}\right]$ albumin Woodruff and Clark showed an exudative enteropathy in $7 / 12$ anaemic children (aged 7-17 months) fed whole cows' milk for at least three months. ${ }^{26}$ Feeding evaporated milk instead of whole cows' milk was followed by a lengthening of albumin turnover half times in four of five patients. In a companion study, Woodruff et al reported a significant degree of microcytosis and lower concentrations of haemoglobin and serum iron $(p<0.01$ at 6 months; $p<0.05$ at 9 months; and not significant at 12 months) in 13 infants fed whole cows' milk compared with 25 infants fed with prepared formula (Similac without iron) ${ }^{27}$ In the study of Fomon et al, 15/38 (40\%) children (aged 4-7 months) fed whole cows' milk compared with $4 / 43(9 \%)$ children fed heat treated (three and a half minutes at $269^{\circ} \mathrm{F}$ or five minutes at $260^{\circ} \mathrm{F}$ ) formula (Enfamil) had occult blood (Hemoccult) in the stool $(p<0.001){ }^{20}$ Similarly, infants fed whole cows' milk had a significantly greater $(p<0.001)$ number of stools positive for occult blood than did the other infants. These differences disappeared in infants aged more than 140 days. All subjects in this study received iron supplements which may account for the fact that no difference was observed between the two groups in terms of haemoglobin concentration, packed cell volume, serum iron, and total iron binding capacity. Fomon et al concluded that pasteurised cows' milk should not be fed to infants before 140 days of age. ${ }^{20}$ The differences between whole cows' milk and heat treated formula milks have led to suggestions ${ }^{28}$ that whole cows' milk should not be given to children under 12 months of age and that so called 'follow on' formula milks should be used in the second half of infancy in preference to whole cows' milk. There is no direct evidence from controlled studies that such formulas do indeed prevent blood loss from the gastrointestinal tract.

\section{Age of ingestion of whole cows' milk}

One of the major criticisms of many of the early studies which purported to show an association between whole cows' milk consumption and iron deficiency anaemia is the rather young age ( $<4$ months in many studies) at which some of the infants were given whole cows' milk. ${ }^{6} 91617$ In the studies of Woodruff $e t$ al, for instance, some infants received whole cows' milk from 2 months of age when it is possible that the developing gut might be more vulnerable to the effects of ingested foreign protein. ${ }^{26}{ }^{27}$ Levels of milk and soy agglutinins have been shown to be considerably higher in infants fed milk and soy formulas within the first three months than in those introduced to these protein antigens after 3 months of age. ${ }^{29}$ This situation prompted the American Academy of Pediatrics to ask: 'Can the change to cows' milk when the infant is 6 months old produce anemia from occult blood loss when the milk is fed in excessive amounts and there is no iron supplementation?' and to conclude that ' . . . there is at present no con- vincing evidence from well-designed research studies that feeding whole cows' milk after 6 months of age is harmful if adequate supplementary feedings are given. ${ }^{30}$ The assumption behind this statement, namely, that adequate iron would be available to infants who consumed an appropriate variety of supplemental foods was refuted by Penrod $e t$ al, who showed an increased occurrence of iron deficiency in infants fed whole cows' milk during the second six months of life, although these workers did not look for evidence of enteric blood loss. ${ }^{31} \mathrm{Wilson}$, in an attempt to answer the question posed by the American Academy of Pediatrics, reviewed detailed dietary histories from the records of his 1974 report and found that $6 / 17(35 \%)$ of his reported cases of whole cows' milk induced enteric bleeding received whole cows' milk for the first time after 6 months of age or later. ${ }^{32} \mathrm{He}$ concluded that 6-12 months of age for the dietary introduction of whole cows' milk may be a vulnerable time for some and that 12 months or older may be a safer age.

Using more sensitive tests for the detection of iron depletion, Sadowitz and Oski were able to assess further the effect of the introduction of whole cows' milk into the diet of infants at different ages. ${ }^{33}$ One of the estimations made, erythrocyte protoporphyin, utilises the fact that there is an accumulation of protoporphyrin in red blood cells when insufficient iron is available to combine with protoporphyrin to form haem. Erythrocyte protoporphyrin can be measured fluorometrically from small samples of blood. In addition to erythrocyte protoporphyrin (a measure of iron deficiency), Sadowitz and Oski measured haemoglobin, red blood cell indices, and serum ferritin (a measure of iron depletion) in 217 infants, aged 9 to 12 months, attending a well baby clinic in whom complete dietary history was available. The introduction of whole cows' milk into the diet had occurred before 6 months of age in $66 / 217(30 \%)$ infants, and $41 /$ $66(62 \%)$ of these had laboratory evidence of nutritional iron inadequacy compared with only $33 / 151(22 \%)$ of those with iron deficiencies fed whole cows' milk after 6 months of age $(p<0 \cdot 01)$. In this study, 19/21 (91\%) infants with iron deficiency anaemia had been fed whole cows' milk before 6 months of age. These results were confirmed in subsequent work. ${ }^{10} 31$ Tunnessen and Oski found that $22 \%$ of infants fed whole cows' milk after 6 months of age had evidence of iron insufficiency (lower mean corpuscular volume, lower ferritin levels, and higher free erythrocyte protoporphyrin levels) at 12 months of age. ${ }^{10}$ In this study, however, there was no significant difference in the proportion of guaiac positive stools in infants fed whole cows' milk compared with those fed iron fortified formula milk. Thus, Tunnessen and Oski concluded that 'the results of our study of infants between 6 and 12 months of age indicate that not occult gastrointestinal blood loss but low iron content of whole cows' milk was the primary factor responsible for iron inadequacy in the cow milk group. ${ }^{10}$

Duration of sensitivity to whole cows' milk Cow's milk induced intestinal tract blood loss 
seems to occur predominantly during infancy and early childhood. Even sensitive infants may tolerate cows' milk later in life without adverse consequences. A 6 week old breast fed infant with rectal bleeding induced by maternal ingestion of whole cows' milk ${ }^{34}$ was found to be completely well and tolerating whole cows' milk at 2 years of age. Wilson et al reported four subjects with proved whole cows' milk induced gastrointestinal bleeding in infancy who were able to ingest whole cows' milk without enteric bleeding when seen at follow up aged 2-3 years. ${ }^{7}$ Most of the 12 children with cows' milk related colitis described by Hill and Milla were tolerating whole cows' milk by the age of 5 years. ${ }^{35}$ Conversely, there have been occasional reports of persistence of milk intolerance. Samuelsson and Werner, for instance, describe a 16 year old boy with a history of watery, sometimes bloody, stools since the introduction of whole cows' milk at 3 months of age whose symptoms resolved on a milk free diet. ${ }^{36}$ The potential relation between early cows' milk sensitivity, whatever its manifestation, and the subsequent development of ulcerative colitis has been suggested for 30 years, but remains unresolved. ${ }^{37}$

\section{Rectal bleeding in exclusively breast fed infants}

There have been numerous case reports of rectal bleeding in exclusively breast fed infants which has resolved when either the nursing mother had eliminated whole cows' milk protein from her diet or breast milk has been replaced by a casein hydrolysate formula. ${ }^{34}{ }^{38-43}$ In the largest series six neonates with rectal bleeding responded clinically to the substitution of breast milk by a hydrolysed casein or a soy protein based formula. ${ }^{38}$ Breast feeding was subsequently resumed in five of six infants; all experienced an immediate recurrence of symptoms. Elimination of whole cows' milk protein from the maternal diet led to a tolerance of breast feeding in two infants but there was no change in the other three. The possibility of prenatal sensitisation to whole cows' milk was suggested by Wilson et al, who reported eosinophilic colitis in a 4 day old neonate who presented with profuse rectal bleeding. ${ }^{43}$ This infant had been exclusively breast fed from birth but her mother had been drinking four to five glasses per day of whole cows' milk. Prick puncture skin testing of the infant and a serum radioallergosorbent test were positive for cows' milk protein.

Berezin et al in an attempt to define more precisely the clinical characteristics and course of milk protein intolerance, studied 22 infants (aged 2-16 weeks), all of whom presented with haematochezia. ${ }^{41}$ Of these 11 were receiving cows' milk, four soy protein, two cows' milk and soy milk, and five were breast fed. All mothers of breast fed infants ingested whole cows' milk during lactation. Rectal bleeding stopped in 19/22 infants within one week of transfer to a protein hydrolysate formula (Nutramigen). In three breast fed infants, breast feeding was continued; each mother, however, was placed on a whole cows' milk free diet. Within two weeks symptoms resolved in these infants. Two months after symptom resolution, 17 formula fed infants were rechallenged with cows' or soy formula. In all instances a recrudescence of the presenting clinical findings was heralded by the reappearance of blood in the stools. In every instance symptom resolution and blood free stools were rapidly achieved after reinstitution of the protein hydrolysate formula feedings. Although these workers went to great lengths, by the process of elimination-challenge-elimination in a similar manner to that initially advocated by Goldman et $a l,{ }^{18}$ to confirm the diagnosis of protein intolerance in their patients, it is not clear from their report whether infants received whole cows' milk or a heat treated formula.

\section{Histological appearances of the colon in} infants with gastrointestinal bleeding

An important feature of the study by Berezin $e t$ al was the demonstration of the histological abnormality associated with rectal bleeding in infants. ${ }^{41}$ Moreover, one of their most important contributions was to examine the mucosal response to elimination and challenge. Typical lesions, manifested by patchy aphthoid ulcerations, were observed by colonoscopy in the rectosigmoid colon in 19/22 infants. Histological findings included surface ulcerations and associated inflammation of the lamina propria and submucosa, marked by substantial eosinophilic infiltration. These appearances had resolved when subjects were re-examined two weeks after elimination of cows' milk or soy protein, or both, from the diet. Furthermore, the characteristic mucosal appearances recurred following challenge with either cows' milk or soy protein. They concluded that in an infant with haematochezia and negative stool culture findings, an initial colonoscopy can identify the characteristic findings of milk induced colitis. ${ }^{44}$

\section{Atopy, allergy, and cows' milk induced enteric} blood loss

This has long been a contentious subject; three aspects, however, stand out from published reports. Firstly, eosinophilic colitis is a manifestation of food allergy and not of cows' milk intolerance per se; several workers have described similar appearances in association with a wide variety of foods other than whole cows' milk including soy, beef, wheat, egg, and pork. ${ }^{35} 45$ Secondly, gastrointestinal blood loss is, in many instances, only one of several symptoms attributable to an allergic reaction; such associated symptoms include chronic diarrhoea, ${ }^{16} 34353846$ vomiting, ${ }^{16} 46-48$ colic, ${ }^{6} 3842$ dermatitis, ${ }^{38}$ and irritability and weight loss. ${ }^{17}$ Thirdly, milk induced colitis with gastrointestinal blood loss is more likely to occur in children with a personal or family history of atopy or other allergy. ${ }^{17} 3545$ 47-49 In Gryboski's series, $14 / 21$ had a positive family history of allergy. ${ }^{16}$ Jenkins et al found that allergic symptoms were more common in milk induced colitis than in selected controls as was a positive family history of atopy related disease $(p<0.006$; Fisher's 
exact test $)^{45}$ and, in the series reported by Hill and Milla, $69 \%$ of patients and $92 \%$ of first degree relatives were atopic. ${ }^{35}$

\section{Pathophysiological basis of cows' milk induced enteric blood loss}

The pathogenic mechanisms that underly adverse reactions to whole cows' milk remain undefined. The association between these reactions and an allergic/atopic diathesis, as indicated above, suggest that immunological mechanisms probably play a part. Attempts to define such mechanisms in cows' milk intolerance have produced conflicting results. In some studies, for instance, increased serum antibodies to food proteins were thought to correlate with positive responses to oral cows' milk challenge $^{14} 5051$ whereas in other studies ${ }^{5253}$ no difference in serum antibodies was found between milk sensitive and normal infants. Similarly inconclusive results have arisen from measurements of lymphocyte transformation and lymphokine production in response to food antigens. ${ }^{54}$ These contradictory findings may be accounted for, in part, by the heterogeneity of the populations studied: some have included those with cutaneous and respiratory as well as gastrointestinal symptoms and children of different ages.

Whole cows' milk induced intestinal tract blood loss seems to occur predominantly in infancy and, as has been pointed out, even sensitive infants appear to tolerate whole cows' milk later in life without adverse consequences. Adverse reactions to whole cows' milk may be related to antigenic challenge of the gut mucosa before adequate development of oral immune tolerance to ingested foreign proteins.

\section{Conclusions}

On the evidence so far available it is not possible to give an estimate of the true prevalence of cows' milk induced gastrointestinal bleeding in infancy, nor has it been definitively established whether or not nutritionally significant enteric blood loss represents a relatively rare idiosyncratic reaction in certain susceptible infants. The Office of Population Censuses and Surveys most recent survey of infant feeding practices in the United Kingdom ${ }^{1}$ found that $5 \%$ of infants were being given liquid cows' milk as a main drink at 4-5 months and this figure had increased to $60 \%$ at $9-10$ months. This latter statistic represents about 72000 infants, and assuming that a third of infants fed whole cows' milk might develop gastrointestinal bleeding, ${ }^{3}$ this represents 24000 infants; there is no evidence that whole cows' milk induced enteric blood loss, with or without anaemia, is so highly prevalent in this country.

Whole cows' milk does contain proteins which can provoke an allergic eosinophilic colitis but this occurs more commonly in infants with an allergic or atopic diathesis. In some subjects whole cows' milk induced gastrointestinal blood loss appears sufficiently great to be nutritionally significant and may contribute to the development of iron deficiency anaemia.
Such an anaemia, however, is more likely to be secondary to the poor concentraton and bioavailability of iron in cows' milk than to occult blood loss from the gastrointestinal tract.

Heat treatment appears to reduce but may not entirely remove allergenic proteins in whole cows' milk. There is no evidence as yet that 'follow on' milks are less likely to produce enteric blood loss than whole cows' milk in children, especially those who show allergic features, in the second half of infancy. Those 'follow on' milks currently available are produced using the spray drying process which does not abolish antigenic sensitising potential. Whether or not different formulations of 'follow on' milks based, for instance, on heat denatured whey ${ }^{55}$ may protect susceptible infants against enteric blood loss remains to be investigated.

Which of the five major whole cows' milk proteins ( $\beta$ lactoglobulin, bovine gammaglobulin, casein, $\alpha$ lactalbumin, and bovine serum albumin) is the prime allergen in infants with cows' milk related allergy is unknown. When the antigens have been more precisely identified, questions will arise about the nature of the mechanism of interaction with the host. Does development of whole cows' milk enterocolitis suggest that a $\mathrm{T}$ suppressor cell population for these antigens has not been developed-that is, an altered regulation of the immune response (oral tolerance) to milk protein? Other mechanisms possibly playing a part in oral tolerance, including circulating antibody-antigen complexes and anti-idiotypic antibodies, have yet to be explored. One approach to further elucidate mechanisms involved in development of intestinal mediated tolerance might be to measure directly intestinal antigen absorption in infants with enterocolitis and correlate this with markers of immune activity.

Results of such studies, though helping to increase the understanding of the mechanisms involved in the phenomenon of whole cows' milk enteric blood loss will not assist in the formulation of recommendations about the advisability of using cows' milk in late infancy. This issue will remain controversial until the prevalence of the phenomenon is accurately established.

This review is based in part on a report prepared for the Nutritional Consultative Panel of the United Kingdom Dairy Industry.

1 DHSS. Report on health and social subjects 32: present day practice in infant feeding: third report. London: HMSO, 1988.

2 Wharton B. Milk for babies and children. BMJ 1990;301 $774-5$.

3 Ziegler EE, Foman SJ, Nelson SE, et al. Cow milk feeding in infancy: further observations on blood loss from the gastrointestinal tract. 7 Pediatr 1990;116:11-8.

4 Elian E, Bar-Shani S, Liberman A, Matoth Y. Intestina blood loss: a factor in calculations of body iron in late infancy. $\mathcal{J}$ Pediatr 1966;69:215-9.

5 Rasch CA, Cotton EK, Harris JW, Griggs RC. Blood loss as a contributing factor in the etiology of iron-lack anemia of contributing factor in the etiology of iron-lack anemia of
infancy. Am $\mathcal{f}$ Dis Child 1960;207:627(A200). infancy. Am 7 Dis Child 1960;207:627(A200).

Wilson JF, Heiner DC, Lahey ME. Milk-induced gastrointestinal bleeding in infants with hypochromic microcytic anemia. JAMA 1964;189:568-72.

Wilson JF, Lahey ME, Heiner DC. Studies on iron metabolism. V. Further observations on cows' milk induced gastrointestinal bleeding in infants with iron deficiency anemia. F Pediatr 1974;84:335-44.

8 Anyon CP, Clarkson KG. Occult gastro-intestinal bleeding in the first two months of life. N Z Med J 1969;70:315-7. 
9 Anyon CP, Clarkson KG. Cows' milk: a cause of irondeficiency $N Z$ Med $\mathcal{F}$ 1971;74:24-5.

10 Tunnessen WW, Oski FA. Consequences of starting whole cow milk at 6 months of age. $\mathcal{F}$ Pediatr 1987;111:813-6.

11 Morris DW, Hansell JR, Ostrow D, Lee C-S. Reliability of chemical tests for fecal occult blood in hospitalized patients. Dig Dis Sci 1976;21:845.

12 Schwartz S, Dahl J, Elleson $M$, Ahlquist D. The 'HemoQuant' test: a specific and quantitative determination of heme (hemoglobin) in feces and other materials. Clin Chem 1983;29:2061-7.

13 Ahlquist DA, McGill DB, Schwartz S, Taylor WF, Ellefson $M$, Owen RA. HemoQuant, a new quantitative assay for fecal hemoglobin. Ann Intern Med 1984;101:297-302.

14 Wilson JF, Heiner DC, Lahey ME. Studies on iron metabolism. I. Evidene of gastrointestinal dysfunction in infants with iron deficiency. F Pediatr 1962;60:787-800.

15 Hoag MS, Wallerstein RO, Pollycove M. Occult blood loss in iron deficiency anemia of infancy. Pediatrics 1961;27: 199-203.

16 Gryboski JD. Gastrointestinal milk allergy in infants. Pediatrics 1967;40:354-60.

17 Kravis LP, Donsky G, Lecks HI. Upper and lower gastrointestinal tract bleeding induced by whole cows' milk in an intestina tract bleeding induced by who

18 Goldman AS, Anderson DW, Sellers WA, et al. Milk allergy. I. Oral challenge with milk and isolated milk proteins in allergic children. Pediatrics 1963;32:425-43.

19 Morton RE, Nysenbaum A, Price K. Iron status in the first year of life. F Pediatr Gastroenterol Nutr 1988;7:707-12.

20 Fomon SJ, Ziegler EE, Nelson SE, Edwards BB. Cow milk feeding in infancy: gastrointestinal blood loss and iron nutritional status. F Pediatr 1981;98:540-5.

21 Thomas DW, McGilligan KM, Carlson M, et al. Fecal alpha ${ }_{1}$-antitrypsin and hemoglobin excretion in healthy human milk-, formula-, or cow's milk-fed infants. Pediatrics 1986;78:305-12.

22 Eastham EJ, Walker WA. Effect of ccows' milk on the gastrointestinal tract: a persistent dilemma for the pediatrician. intestinal tract: a persistent
Pediatrics 1977;60:477-81.

23 Kilshaw PHJ, Heppell LMJ, Ford JE. Effects of heat treatment of cows' milk and whey on the nutritional quality and antigenic properties. Arch Dis Child 1982;57:842-7.

24 May CD, Fomon SJ, Remigio L. Immunologic consequences of feeding infants with cow milk and soy products. Acto Paediatr Scand 1982;71:43-51.

25 McLaughlan P, Anderson KJ, Widdowson EM, Coombs RRA. Effect on heat on the anaphylactic-sensitizing capacity of cows' milk, goats' milk, and various infant formulae fed to guinea-pigs. Arch Dis Child 1981;56:165-71.

26 Woodruff CW, Clark JL. The role of fresh cows' milk in iron oodruff CW, Clark 2 . The role of fresh cows

27 Woodruff CW, Wright SW, Wright RP. The role of fresh cows' milk in iron deficiency. II. Comparison of fresh cows' milk with a prepared formula. Am F Dis Child 1972;124: 26-30.

28 Oski FA. Is bovine milk a health hazard? Pediatrics 1985;75: $182-6$.

29 Eastham EJ, Lichauco T, Grady MI, Walker WA. Antigenicity of infant formulas: role of immature intestine on protein permeability. $\mathcal{F}$ Pediatr 1978;93:561-4.

30 American Academy of Pediatrics, Committee on Nutrition. The use of whole cows' milk in infancy. Pediatrics 1983;72: 253.

31 Penrod JC, Anderson K, Acosta PB. Impact on iron status of introducing cows' milk in the second six months of life. 7 Pediatr Gastroenterol Nutr 1990;10:462-7.

32 Wilson JF. Whole cows' milk, age, and gastrointestinal bleeding. Pediatrics 1984;73:879-80.
33 Sadowitz PD, Oski FA. Iron status and infant feeding practices in an urban ambulatory center. Pediatrics 1983;72. 33-6.

34 Chong SKF, Blackshaw AJ, Morson BC, Williams CB, Walker-Smith JA. Prospective study of colitis in infancy and early childhood. F Pediatr Gastroenterol Nutr 1986;5: 352-8.

35 Hill SM, Milla PJ. Colitis caused by food allergy in infants. Arch Dis Child 1990;65:132-40.

36 Samuelsson SM, Werner I. Milk-induced colitis. Acta Med Scand 1966;180:145-52.

37 Glassman MS, Newman LJ, Berezin S, Gryboski JD. Cows' milk protein sensitivity during infancy in patients with inflammatory bowel disease. Am $\mathcal{F}$ Gastroenterol 1990;85: $838-40$

38 Lake AM, Whitington PF, Hamilton SR. Dietary protein induced colitis in breast-fed infants. $\mathcal{J}$ Pediatr 1982;101: 906-10.

39 Shmerling DH. Dietary protein-induced colitis in breast-fed infants [letter]. 7 Pediatr 1983;103:500.

40 Klein E, Shvartzman P, Weizman Z. Blood-streaked stools in two breast-fed siblings. F Fam Pract 1990;30:713-4.

41 Berezin S, Schwarz SM, Glassman M, Davidian M, Newman LJ. Gastrointestinal milk intolerance of infancy. Am $\mathcal{F} D$ is Child 1989;143:361-2

42 Pittschieler K. Cows' milk protein-induced coltis in the breast-fed infant [case report]. I Pediatr Gastroenterol Nutr $1990 ; 10: 548-9$.

43 Wilson NW, Self TW, Hamburger RN. Severe cows' milk induced colitis in an exclusively breast-fed neonate. Clin Pediatr (Phila) 1990;29:77-80.

44 Berezin S, Schwartz SM, Glassman M, Davidian M, Newman LJ. Gastrointestinal milk intolerance of infancy. Am f Dis Child 1990;144:17.

45 Jenkins HR, Pincott JR, Soothill JF, Milla PJ, Harries JT. Food allergy: the major cause of infantile colitis. Arch Dis Child 1984;59:326-9.

46 Raafat F, Castro R, Booth IW. Eosinophilic proctitis with giant cells: a manifestation of cows' milk protein intogiant cells: a manifestation of cows' milk protein
lerance. $\mathcal{F}$ Pediatr Gastroenterol Nutr 1990;11:128-32.

47 Gryboski JD, Burkle F, Hillman R. Milk induced colitis in an infant. Pediatrics 1966;38:299-303.

48 Powell GK. Milk- and soy-induced enterocolitis of infancy f Pediatr 1978;93:553-60.

49 Rubin MI. Allergic intestinal bleeding in the newborn: a clinical syndrome. Am F Med Sci 1940;200:385-90.

50 May CD, Remigio L, Bock SA. Usefulness of measurement of antibodies in serum in diagnosis of sensitivity to cow milk and soy proteins in early childhood. Allergy 1980;35: 301-10.

51 McDonald PJ, Goldblum RM, Van Sickle GJ, Powell GK. Food protein-induced entercolitis: altered antibody response Food protein-induced entercolitis: altered antibody

52 Saperstein S, Anderson OW, Goldman AS, Kniker WT. Milk allergy. III. Immunological studies with sera from allergic and normal children. Pediatrics 1963;32:580.

53 Dannaeus SG, Johansson SG, Foucard T, Ohman S. Clinica and immunological aspects of food allergy in childhood. I. Estimation of IgG, IgA and IgE antibodies to food antigens in children with food allergy and atopic dermatitis. Acto Paediatr Scand 1977;66:31.

54 Van Sickle GJ, Powell GK, McDonald PJ, Goldblum RM. Milk- and soy protein-induced enterocolitis: evidence for lymphocyte sensitization to specific food proteins. Gastrolymphocyte sensitization to
enterology 1985;88:1915-21.

55 Heppell LMJ, Cant AJ, Kilshaw PJ. Reduction in the antigenicity of whey proteins by heat treatment: a possible strategy for producing a hypoallergenic infant milk formula. Arch Dis Child 1984;51:29-36. 